\title{
Components of School-Based Management in the Educational Systems of Several Countries
}

\author{
Kewmars Fallahi ${ }^{1} \&$ Nematallah Matin $^{2}$ \\ 1 Faculty member of Organization for Educational Research Planning (OERP), Commercial Management \\ Department, Management and social sciences Faculty, Tehran North Branch Islamic Azad University, Tehran, \\ Iran \\ ${ }^{2}$ Faculty member of Organization for Educational Research Planning (OERP) \\ Correspondence: Kewmars Fallahi, Management and social sciences Faculty, Tehran North Branch Islamic Azad \\ University, Tehran, Iran. E-mail: kewmarsf@gmail.com/N.Matin29@yahoo.com
}

Received: May 16, 2016

Accepted: May 27, 2016

Online Published: June 26, 2016

doi:10.5539/mas.v10n9p161

URL: http://dx.doi.org/10.5539/mas.v10n9p161

\begin{abstract}
Manage school axis, as one of the Strategies of reform of education in the educational systems are in this solution wanted very much to the requests provides and decisions to the school for raising the level of education shown, experience of the school education axis, suggest this point is that what decisions to different levels of the school are close to access to society to attend enthusiastically with quality, guarantee more and the participation of people in the administration of schools in the framework of the policies of training adults national increase,. In the educational system school axis, passing through the administrative focus on the delete lack of concentration, subject to submission provides more from the center to the local and strategy more forward-thinking than simply hoping for programming textbooks based on local needs and participation of teachers and even students in the decisions related to school. In this check the chief aim" comparative compared solutions to manage school axis in the systems of different educational "It is using the method of descriptive name "Adapting the structure of the educational systems of the school of "and "comparison pivotal school" and "study of the schools in the system of training 30 countries of the world".
\end{abstract}

Keywords: the educational system, the structure of the solution, pivotal school, provides

\section{Introduction}

The world today, the scene of the courtesy mirror eye in the field of economic, political, social and cultural and battleground Premiers Melbourne and founder of the crisis of different. These affect the capacity and difficult to all view of system training, education than heavy and complex than the past. The growth of hurried knowledge, enhancement of the international community, the pivotal slogans of "Education for All" and "all for education", "Education for living" and the issue of education and environment, the growth of population, opportunities to educate, education lifelong, lack of concentration, change and instability including the concept of twisted wires that the training in his challenge revealed. In this view only by relying change premise that with these challenges and control of this crisis will there and the only efficient the organization training innovation also in the field and the duty and the structure of the organization and the change and evolution of the constitution, to nurture it. Innovation management education, the features of the Colombian achievement in should not be construed as an endorsement of the recent decades. This, particularly in the advanced countries, the measurement eye in means you have school there. What this transformation is worth attention to tend the educational focus removal. In several countries, efforts and time to access to create superior school and of the check and do activities and research led the realm manage education such that finally more of them coming to the idea of "school systems". Results of this effort and study the capacity of the Center for the school and the educational system of school, axis is leg.

\section{Relevant Question}

During three ten the fascinating change in the educational system of the mind planners program and senior managers of the ministry of education to have a system of education with focus on the structural and earth is the volume of the remains of a hundred years of Court experience democracy and the concentration of the staff and inefficiency in school, this system requires serious to enhance overtly and performance. It seems that one of the 
problem and the problem that must be solved for it be sure real, the school, the output and quality of the organization of the school in Iran during his life only as changed and the method of work and its content less changes sensible and fundamental. The Metamorphosis and the schools of the national government of the people, nonprofit, would squander delegation and like it, reflects this fact is that what has been expected not brought. The education focused intensity, in many cases, Marburg thinking and responsiveness of teachers and students is and low motive and high scholastic drop in taken the system needs presenting strategy more forward-thinking than simply hoping the new, practical, dynamic and conformity with the terms and the facilities of the society. In this regard, was one of the ways of attention to the pivotal school is that in the system of education other test and hygienically and covenant. "Pivotal School" of concept like autonomous school, his school and his school control memory of one of the famous cartoons that can be the instrument of the authority delegated. The pivotal school a call for participation teachers, managers, students and parents in the administration of the school and are a kind of trust and confidence to the capabilities of them. Hygienically approach "School" pivotal takers it affects to the lack of concentration management arenas immobilize most and a process that "to powers opportunity to fields of programming scholarships devoted the resources and man power for school students and knowledge in and in some cases also the position of the power of the higher reference to the top of the lower change that (Caldwell, V., 1992), compassion which induced the change (Abvdahv, 1383). It is worth mentioning that in the system centralized, education by the same forces that control other functions of social and political and cultural procession to and buffs in circumstances, and development very complicated will be (Newlon, 1939) for attention to the issue of culture in various systems training is very important. And about the sponsorship of the delegation of the key words to pre, spectrum of the theory and opinion couple such divergent. A school of the pivotal of democracy they know and this believe that "if education to the purpose of the right people and principals to be all the people on it (Newlon, 1939). Group unit blocks also System Programming someone the top better. What the important influence on how the school and investment of society, as Williams, in the present world for the ideal school, must first to understand the integrity of a ideal school and elements of the influence of the reached 0 on this basis in each of the Focus nationalist training, half focused vena centralized, school different position (Williams, 2002).

\subsection{The Importance of a Wider Debate about the Subject Check}

Magnitude and concentration of the classroom education in Iran and paying attention to the varied issues like much of the population under the cover of the school, the codification and Compilation and print textbooks, built or processing tools equipping school and materials to help education and. More than couple of York in proximity to links to optimizing the main draft term of activity would be should not be construed as an endorsement of the sections of the public education and specialized Colombian achievement. In the economy choice system for now this world disconcerted him no longer problem of the broad river lying between before the experience of the most powerful nations systems of education. For the comparative study of the educational systems of the world can a user interface switches over to the advantage of the structure of a system of education size and to reform immediately. Perhaps structural improve educational system and can cause promotion performance mannerly genius part of education and the increase in the dignity attend enthusiastically and the resources and time of popular opportunities and non-state and Modares separate from the loss of resources, increased responsibility for vulnerability, anonymous, confidence and growth and sign students teachers comforting daydreams. Without understanding how the structure of the ideal, thought school also axis way to where. This E.M. Hanson (Note 1) well of "Strange and longing to management based on the school caused subjects like understand clear structural form of the features of the executive and efficiency of less attention" results research also indicate that the situation of education in advanced countries of his process management arenas and to the lack of concentration subordination. The acceptance of this belief, has reform in different countries of the world is the study of this study to reach the goal of aid. Among these, very much preapproach defines the educational systems of the world can experience for ambiguity of the nationwide system of education.

\subsection{General Aims}

The chief aim of this research comparative compared solutions to manage school axis in different systems of education in different systems of education and adapting the structure of the educational systems of the position of the school in them and adapting the authority has been granted to the lower levels and in the schools of the secondary aim of this study.

\section{Research Questions}

This study in finding the answer to three questions under: 1 . what is the role of schools in the various educational systems? 2. What is the school-based component in the educational systems of the world? 3 . The rate of the 
authority delegated to the levels below the province - the school in the educational systems?

\subsection{History Research}

"Alfred Marshal" with the most valuable investment education resources considered, he believed this is an inventor can cost education of a city for (Tosi, 1369). Comment human capital also says:" education in the Most Great computing is that man can there and this case what the individual and social in comparison with any other investment more efficiency, provided that education is correct and needs economic, social and cultural people and communities (Aminfar, 1374). Scheffer (1992) pointed out that responsibility finance human resources required for with the crisis on the global development with more education to have been (Robinson, 1378) and important must be in the school happen, Thus the structure and quality of school and how to manage it will be very valuable. School management, base complex set of concepts and the process by which a large number of factual information and new terminology can be described (Fleming, 1988), and schools had increased under the title such as: Autonomy, decentralized management, decentralization, participatory decision-making, etc., have expanded the scope of their activities. This diversity names arising from different outstanding provides in the decisions and the structure of the operation has been different in different schools world executed, but in the name of more than all a school systems". Along with the creation of a school term trend toward increased education authority schools emerged decision. Manage education school new funding axis is Cairo Institute of morals and human relations of the three on the principle: Authority, partnership and flexibility(Hanifi, 1379) in other words, "school systems" means nationwide system of education opt, Collaborative planning in education and away from the focus on decision-making and planning (Pouya, G., 1378) and is meant to provide favorable conditions and atmosphere for spontaneous voluntary participation, and the meaning of providing terms and favorable atmosphere for his presence انكيخته voluntarily, creative and freely coaches in the guidance and management and participation educational activities and تربيتى school in four wood general policies and policy aspects constitution will attend enthusiastically. (Karimi, 1378)," school systems" And is meant to provide favorable conditions and atmosphere for the voluntary spontaneous, creative freedom and the participation of parents and teachers in the conduct and management of educational activities and school education, basic education policies in the context of the overall policy and is education. (Karimi , 1378), "school-based" means that everything, including the way we work, the program, the type of teacher management method and type of assessment and evaluation tools, training, and even a "school" set (Trench, 1378). The name derived from various administrative procedures in the field and has been given the following variables:

Increase school autonomy and freedom of action, increase school accountability, increase the power of school policy, increasing the scope of decision-making within the school and within the scope and increase the members of the Board of Trustees and Board of each school. However, in this case the school is central to the meaning of decentralization should reflect a little, because it is possible that the decentralized system of school-based model implemented. Resources and their decisions to headquarters (at the national or provincial or regional) meet (of interest, 1376). According to these, can be a school-based approach outlined the following features.

\section{Changes in Traditional Practices in Education Management}

Delegate decision-making authority to school and subordinates, consider the school as the basic unit of change and eventually strengthened and stimulated by delegating decision-making authority at the school level. Now, the process of decentralization in the management of educational systems in developed countries has led school-based European, and educational systems developed in the past few decades, a move to transfer authority to the school level that has led to the decentralization law. The truth is that despite the focus on the decision of the related to the lesson, examinations and employment of employees in a system of education to any kind of educational reform cannot hope, except that provides innovation and solving problems related to school, to a school cannot position to analyze and after the value of diagnostics operation and results, policies educational based on the defined, could not be the Word" axis school" in. . In Italy, from 1974 and then, by the board of education at the school, district, province and country, significant changes have occurred in the Department of Education. Changes of this kind in Sweden and the Netherlands also viewed. In summary it can be said that as a result of the above events, similar patterns emerged in different countries is that governments, at national or provincial or regional level, the central role it will play an important part in. In this level of the framework of program and examinations, determine or suggestions and based on the general expectations of the school and educational system is and at the same time, A movement towards decentralization in education systems can be seen that aims to shift the responsibility and authority to the school to meet these expectations, they can make decisions at the school level. It is expected that schools focused manner within the limits that have been set, they become increasingly autonomous. Normally at school, more emphasis is centered on two principles Delegation of authority and independent budget. 


\subsection{Delegation of Authority}

Delegating skills, most likely, the most useful management tool for someone who tries to get things done by others. Delegation to the process of assigning tasks to subordinates who usually is accompanied by a responsibility manager, shed. It must be subordinate to the higher authorities delegating that the organization must work with high efficiency, for any high official or senior person cannot be complete or accurate direct and supervise the work of the organization (Lester, 1377).

Delegation of authority provides to the real nature of man dipped headlights levels helps. This method places the organization that the appointment of incompetent people to stop. The important thing is Delegation of authority that enables managers to their original tasks, which is to address the future of the organization and development of future managers do not routinely monitor themselves caught (Parkinson, 1376). Delegation of authority to please their energy consumption helps all the things that really matter. It "Drucker" The system of high involvement of senior managers in the senior management prevents managers, which in turn frees up their innovation spreads.

\subsection{Independent Budget}

Centralized budgeting, rarely motivation or incentive for efficiency and that promoting diversity in educational activities and services necessary to detect and identify approaches to more effective and efficient in teaching and learning is often not progress. Finally the main factors educational environment, i.e. managers schools, teachers, parents and students that can in the effective use of the resources of the school role play. Ignore. The researchers believe that the way to solve this problem, create autonomous schools. The budget of the schools one and a cloth assigned in decisions related to Madras, people more participation and variety and diversity presenting services and activities of educational programs in schools and between schools encourage, to this way of the choice of the type of education and training for students and parents that guarantee. In recent years manage financial affairs in schools in many countries focus removal and local management and financial independence in school. Also to provide outsourcing in other affairs like that of the educational programs and the value of the diagnostics has been spread (Mateios \& Robinson, 1378), Edwin Ray Gatry research Piers analyze the confirmation. They are hesitant via assignment of resources to focus on and also shape, be justice and equality in the enjoyment of education guarantee. In their opinion, education is an important tool to create and promote the value of the triple equality, efficiency and freedom.

Organizations according to their specific conditions, to govern and to achieve organizational goals, the methods they use centralized or decentralized. Of course line and detailed border between concentration and focus removal can be traced. Both of these are relative and absolute find democratic societies do not successful organizations of both. This organization in the determination of the objective of the general has been focused but in the stage of implementation, Delegation of Authority provides. Background Research: Research conducted inside and outside the country, shows that in recent years, school systems, have a tendency to decentralization. We can say that now, through the centralized management of educational institutions, do not have much success. Given the shortcomings of the centralized system, the decentralization of the education system is a necessity. Educational systems should be given the resources, capabilities and needs of each region, they proceeded to decentralization. However, the basic foundation and to determine overall goals and targets, it is necessary to use the centralized system But the Administration, Decentralization better results will follow. The most obvious type of decentralization and school-based education strategy to improve the quantity and quality of education is considered. School-based index, flexibility, partnership, Delegation of authority and decentralization are. Among the advantages of decentralization for school-based education, improving educational quality, student achievement, increase job satisfaction of teachers and administrators, various educational activities and improve the performance of schools.

\subsection{Central School in Iran}

School-based management in a relatively short history in the education system in Iran. In the late 1370 (1991), social demands of education increased. In those years, school-based policy with components including participation, decentralization and Delegation of authority, as the strategy of the Ministry of Education, out of the crisis performance, net of expenses was deemed. .Look at the speeches and writings of the Ministry of Education in the year 1377 to 1380 solar (1998 -2001), show that financial concerns, lack of funds and problems as the origins of the ideas central school, were introduced (Matin, 1383). The school was considered pivotal and regulations also adopted for its implementation in schools, the objectives and strategies were defined it thus: "manage school axis that summary strategy more forward-thinking than simply hoping for ease of access to the goals attend enthusiastically, via outsourcing part of the renaming decision which defined school. Pro constitution the participation of administrators, teachers, students and a parent them in the decisions and clear the goals and wants, 
to schools to merely means from the letters of the dies except to be planning school, the role of the main responsibility.(Regulations implementing the schools, 1380) on this basis the most important objective of the school systems in the system of education in Iran was: The development of public participation and providing for their realization in the education sector, decentralization of the administrative system, improve the efficiency and ability of schools, the opportunity to comment and participation of all students in educational leadership and play an active role in managing School, granting independence and authority for planning in various fields of education, culture and business schools, changing the bureaucracy in organizations and departments of education staff in the role of advocacy, monitoring and support measures school performance and optimal use of capacity and independence capacity of administrators, teachers and parents to achieve the objectives of Higher Education (According to the Institute of Education, 1378). In connection with the above approaches, the Minister of Education at the time, the ministry's policy outlined this "schools core principles, principles and policy Mhvrha.ayn possibility of administrative circulars and instructions increases and with authority the principal director and teacher of human dignity and self-respect and self-reflection will be upgraded. Participation administrators, teachers and guardians of students in decision-making and school management as well as discuss decentralization and delegation of policy principles in the implementation of school-based significant "(speech at the meeting of directors of the provincial Minister of Education, February 1377) recent decades, educational system, by moving towards decentralized management, implementation of decentralization and the creation of autonomous schools to some extent provided Since 1382, a school-based initiatives within the framework of Article 88, the number of public schools in the country, was conducted. Under the plan, the school administrators in the fields of education, culture, administrative and financial Delegation of authority, but also for the realization of a central school in Iran, obstacles faced and could be one of the causes of the failure to implement it, shortages of skilled labor and the strength of the educational system's decentralization. At the same time the research was done on this issue and about the education of school-based and school-based realization of the following to the point:

(1) According to the cooperation and participation of the public in the fields of culture, family and other community institutions.

(2) Assessment of the status quo educational system in the country.

(3) Comparative studies and the experience of other countries.

(4) Awareness to people.

(5) Education and training of managers and employees.

(6) Run the ball, focus.

(7) Develop a comprehensive, systematic and lawful.

(8) Good infrastructure through the creation of facilities, legislation and agreements and taking the necessary funding.

(9) Necessity of changing roles and define new roles school-based framework.

(10) Civic education development and adoption of decentralization in all institutions.

(11) Developing indicators for school-based system.

(12) Cooperation experts from within and outside the education system (Fallahi, 1389).

In addition, the research-based school system variables include:

(1) In view of the school as a social system Professional.

(2) Collective collaboration and decision-making at school.

(3) Delegation of authority.

(4) Decentralization.

(5) Flexible school management method.

(6) Enabling administrators and school staff.

(7) Monitoring, support of training and education of school-based initiatives.

(8) The clear and important find all individuals active in school.

(9) The Cairo Institute charter school administration.

(10) Recognizing the independence of the school. 
(11) Taking advantage of potential employees.

(12) Good use of facilities and capacity of local, Professional and social teachers.

(13) Preparation for dynamism and innovation at school (Fallahi, 1389).

The school's position in the structure of the educational systems in the world: In the present study the educational system of the Islamic Republic of Iran with the 15 countries studied. Comparative study of fifteen systems and data analysis of the research in the field of educational policy, represents that: Educational systems in South Africa, Iran, Japan, France and Egypt are run as centralized educational systems of Germany, Australia, England, the United States of America, Canada and India are concentrated policies and educational systems Malaysia half of it is concentrated, however, in all countries of the desire for decentralization of all or part of the educational system in such a way can be seen In most countries studied, the main focus is the government planning policies are more systems, while basic education to 9 years have had two first and second periods of theoretical, technical and professional and tailored structure decentralized systems have created. One of the common aspects of education systems, patterns and structural strategies is the focus of this process of reform must happen slowly. Table ahead, the structure and components of the educational systems of some countries of the world with the educational system of the Islamic Republic of Iran have been revealed.

Table 1.

\begin{tabular}{ccc}
\hline Row & $\begin{array}{c}\text { The name of the } \\
\text { country }\end{array}$ & The components: drafting or select lesson books of \\
\hline 1 & Germany & The schools. \\
2 & Spain & The Ministry of Education- states- autonomous communities \\
educational states, School
\end{tabular}

Table 2 .

\begin{tabular}{|c|c|c|c|}
\hline Row & $\begin{array}{l}\text { The name of } \\
\text { the country }\end{array}$ & $\begin{array}{l}\text { The components: the structure of the organization and the organization education } \\
\text { each country }\end{array}$ & $\begin{array}{c}\text { The structure of } \\
\text { the type }\end{array}$ \\
\hline 1 & Argentina & The government of the local provinces & Decentralized \\
\hline 2 & Albania & Under the ministry of education and higher education & Centralized \\
\hline 3 & Germany & The joint commission of the federation, states, Municipalities & Decentralized \\
\hline 4 & Spain & $\begin{array}{l}\text { The dynamism of participation and educational institutions }=\text { concentration on the } \\
\text { management of non-partisan centers of public education }\end{array}$ & Semi-centralized \\
\hline 5 & Australia & The central authorities of each state separately identify curriculum & Decentralized \\
\hline 6 & South Africa & The government of the local provinces & Decentralized \\
\hline 7 & UAE & The government of the United Emirates Arabic- the state of the federal & Semi-centralized \\
\hline 8 & Indonesia & $\begin{array}{l}\text { The structure of the organization of the ministry of culture and education consists of } 7 \text { is } \\
\text { unit }\end{array}$ & Centralized \\
\hline 9 & England & The Ministry of Education supervision institutions local education (into) & Decentralized \\
\hline 10 & America & State of the federal & Decentralized \\
\hline 11 & Italy & Education classroom municipalities & Decentralized \\
\hline 12 & Brazil & Axis School & Decentralized \\
\hline 13 & China & $\begin{array}{l}\text { A control of the government, central government, province - Towns and villages has } \\
\text { education departments. Focused educational support for ethnic minorities }\end{array}$ & Centralized \\
\hline 14 & Japan & The Ministry of Education & Decentralized \\
\hline 15 & Sweden & The Government and provincial councils, municipal in the school of private & Decentralized \\
\hline 16 & Chile & Axis School & Decentralized \\
\hline 17 & Ghana & Ministry of Education, politics and focus also follows oppositionist & Centralized \\
\hline
\end{tabular}




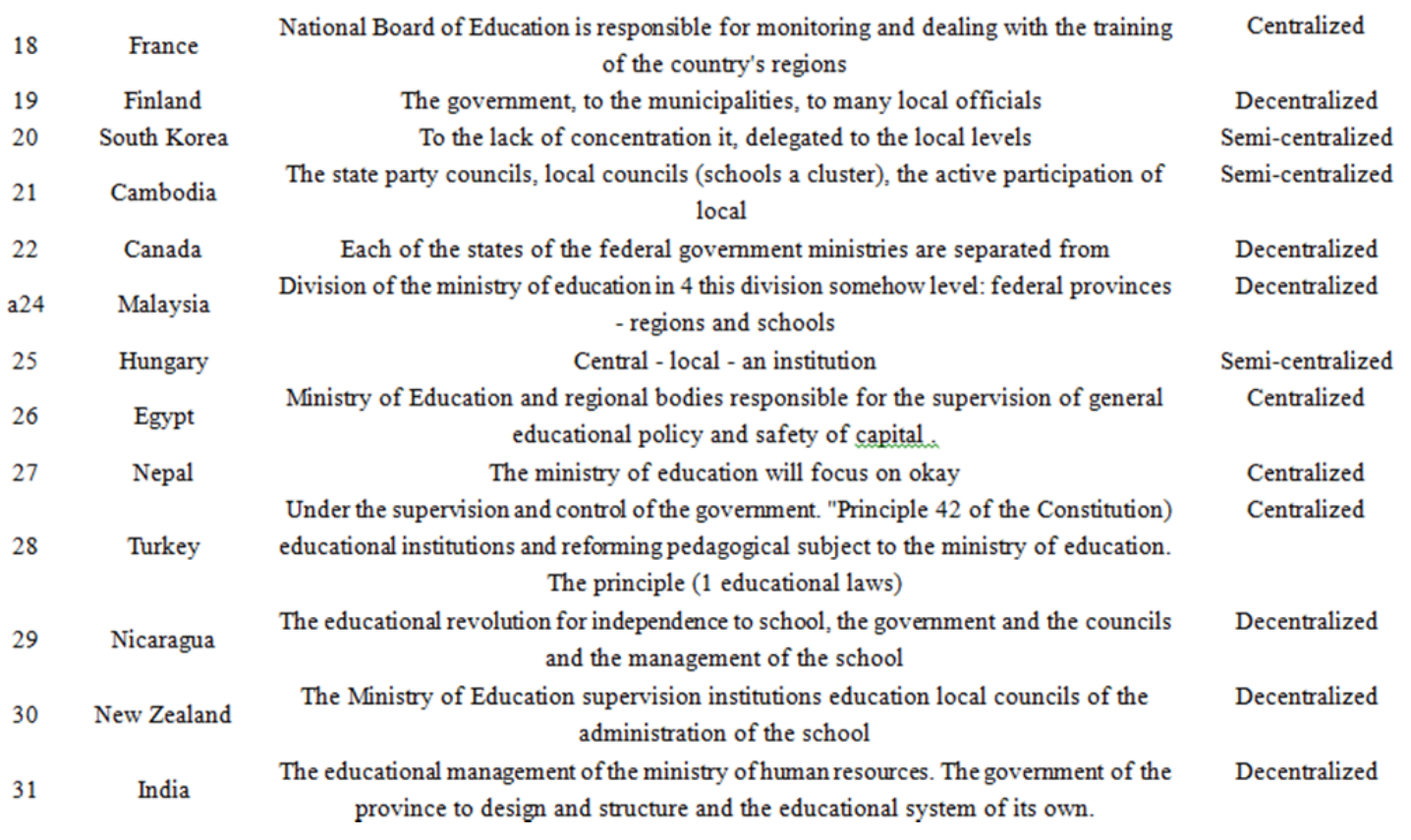

Table 3.

\begin{tabular}{|c|c|c|}
\hline Row & $\begin{array}{l}\text { The name of } \\
\text { the country }\end{array}$ & Name components : curriculum development \\
\hline 1 & South Africa & Formulation and adoption of a common curriculum by state \\
\hline 2 & Albania & The Council of teachers which includes the dialog is training \\
\hline 3 & Spain & $\begin{array}{l}\text { The Period of the responsibility of the state and autonomous communities in the } \\
\text { secondary education in national level and by the ministry of education, but voluntary } \\
\text { lessons to students. }\end{array}$ \\
\hline 4 & Australia & The central authorities of each state separately identify curriculum \\
\hline 5 & UAE & The Ministry of Education \\
\hline 6 & Brazil & Education-federal classroom \\
\hline 7 & Turkey & Under the laws of the ministry of education \\
\hline 8 & China & Ministry of Education and the Council under its auspices \\
\hline 9 & Sweden & $\begin{array}{l}\text { And explain (the highest rank decision municipalities). The necessary norms. The } \\
\text { committee of the local municipal). The scheduled table education (the school). }\end{array}$ \\
\hline 10 & Ghana & The Ministry of Education \\
\hline 11 & France & $\begin{array}{l}\text { The national board of education and responsibility of supervision and cases and rubric } \\
\text { and the general of the education ministry determines }\end{array}$ \\
\hline 12 & Finland & $\begin{array}{c}\text { The 9-year-old "universal and courses over to the local authorities and schools, } 0 \\
\text { (involves the national council of education), educational programs supplementary } \\
\text { schools secondary education (state) }\end{array}$ \\
\hline 12 & Cuba & The Ministry of Education classroom \\
\hline 13 & Malaysia & $\begin{array}{l}\text { National schools (Malay) and national schools (other languages : Mandarin, Tamil, etc.) } \\
\text { at the primary level. Develop a national curriculum in } 1988 \text {, regularly reviewed. }\end{array}$ \\
\hline 14 & Egypt & $\begin{array}{l}\text { The Ministry of Education is responsible for all matters of educational policy, including } \\
\text { safety of capital; determine curriculum, books and teaching aids are provided. }\end{array}$ \\
\hline 15 & Mexico & The Ministry of Education classroom \\
\hline 16 & Namibia & Formulation and adoption of a common curriculum by state \\
\hline 17 & Nepal & As common in the entire country is \\
\hline 18 & New Zealand & The councils of the schools \\
\hline
\end{tabular}


Table 4.

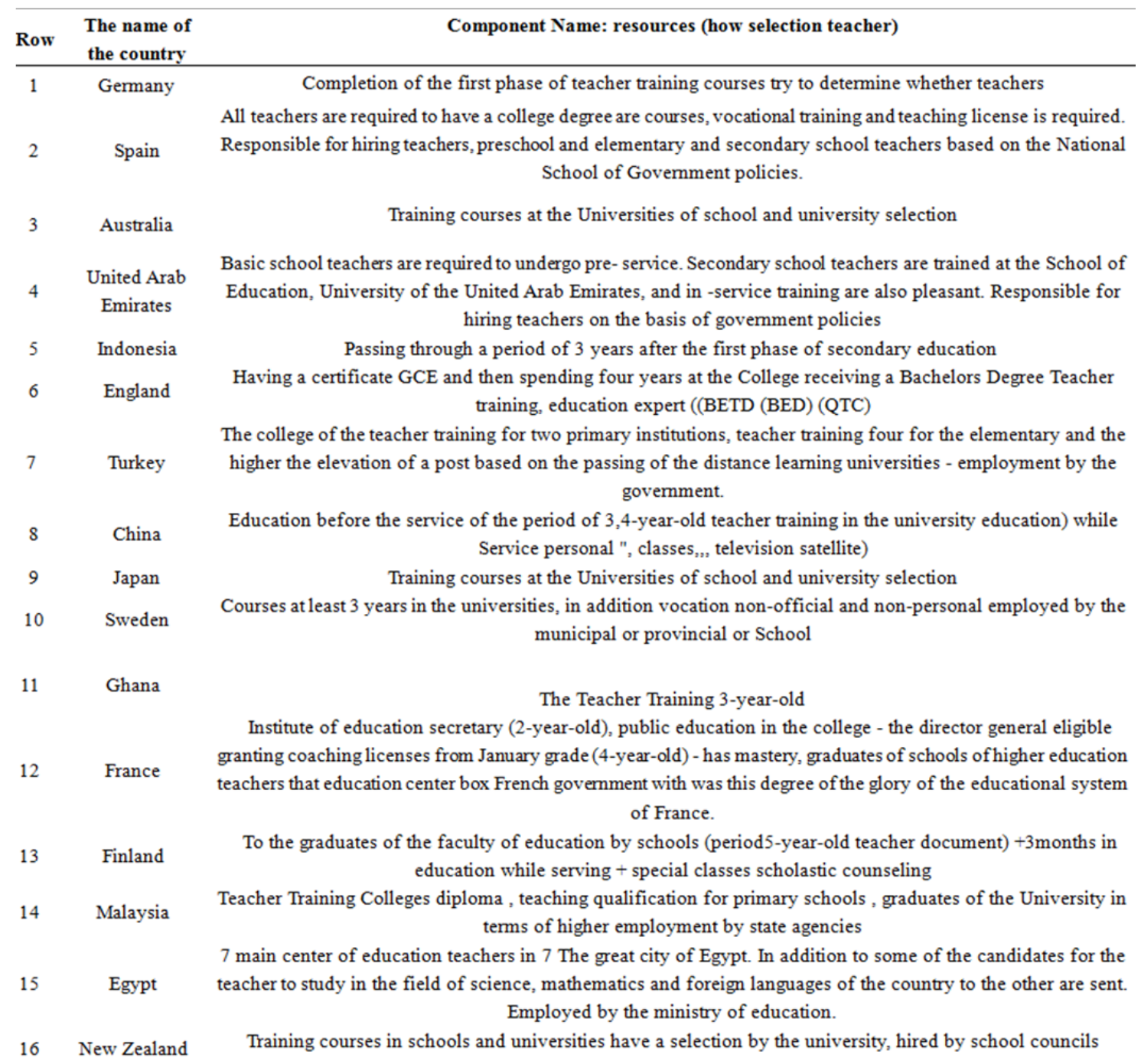

\section{The Result}

The concepts, theories and models related to a school, as a decentralized organization and the correction in developed countries is education, shows that school-based management product to focus systematic approach and contingency operations in education. According to school policy thrust, the redistribution of power and Authority high levels of the educational system in the lowest and at the same time the main operational center (school) there. With regard to the comparison table and mentioned "school-based component" in the educational systems of the world and study their provisions, these components will be based on four principles on the following:

(1) Participation

(2) Decentralization

(3) Flexibility

(4) Delegate

Of these four principles, "participatory" has a higher priority central role. The other three principles, procedures and participation. In other words, proper implementation of school-based education organization that the centralization of the country, give way to decentralization. Management of education is to adopt flexible working people. Participate seekers has legal authority. Thus reflecting the principle that education is built based on the role and highlighted the excellent "collaboration and collective cooperation" in school is completely obvious and sensible. Also, it can be concluded that the effectiveness of the educational challenges faced in various aspects of their activities and occasionally also its structure and change is relative. Given the importance of theories focus on 
the organizational structure and the position of the decentralization of education in the country, the most important point that should be considered include: the ambiguity of roles and new responsibilities, the problems caused by the multiplicity of recognition, ignorance or lack of awareness of decision-makers, inequality and the concentration of financial and human resources, lack of preparation for reception of low-level decision-making authority, lack or shortage of qualified and specialized employees and managers, unfamiliarity with laws and regulations, lack of organizational control system, these are the main barriers tend to be focusing on the core operations (schools) or the management of the school.

\section{References}

Allen, \& Lee, E. (1993). A study of relation shipprincipals and teachers perception of the site based management concepts and preclimate in llinois elected President George predissertation abstracts international. Biometric Identifiers, 55(9).

Anderson, L. W., \& Kart Hwohl, D. R. (Eds.) (2001). A taxonomy for learning, teaching and assessing: A revision of Bloom's Taxonomy of educational objectives: Complete edition. Technology \& Assessing Group, 2004.

Anne, H. D. (2002). School-based management through cluster schools: A case study from cormbodia. Based Managemen, Internet.

Beare, H. (1992). The restructuring of pre and pre systems: comparative perspective. In: Harman, \& A. Bradlay (October, 1992). Crusaders in Detroit Right to Keep Seats Complex Institutions Education Week, 12(7), $1-10$.

Brandon, P. R. (1994). Teacher involvement in pre-conducted needs assessment-issues of decision-making sponsorship and validity. ZG: Heak \& Notochord. German Broadcast indicates bring a bottle. Education Week, 12(7), 1-10.

Briggs, K., \& Wohlstetter. (October, 1999). The entire key of successful pre-based management while acknowledging the Internet.

Brown, D. (1990). .Decentralization and School-Based Management. Falmer Press.

Burger, D. (September, 2008). Sunny South had been waged against an endorsement yearbook. Governmemt Communication and Information System.

Burros, B. (2000). The Japanese Ministry of Education, Culture, Sports, Science and Technology, Science and Culture. Monbukagakusho, Gorvernment of Chonburi Football Club, Tokyo, Monbusho Education, Ministry of Education.

Carlson, R. (1989). Restructuring Schools. Washington DC: Public Schools Publications.

Chirs, A., \& Talcut, P. (1951). Someone cited: As education producer and it had. Allyn and Bacom, 62-67. Sergiovanni, T. afterwards.

Chubb, J. (1990). America's Public Schools: Choice Is a Panacea. Brooking Review, 8(3), 4-12. DC: King Abdullah.

Cole (1993). A study of the relationship between site management, teacher decisional participation and school climate. Global education digest 2008 UNESCO, 21-A.

Danso, G. (2000). International, about us and academics: Teacher implementation \& student outcomes. They may yet present career of the student of the American Education Research Association. International San Francisco, Aniska, Internet.

Demmer, Sandra, B., \& Audrey, D. (February, 1996). Nobek afterwards, School-Based Management, 3, Internet.

James, F. (2002). Leadership in schools. Kogan LTD.

James, T., \& Levin, H. M. (1983). Public dollars for private pre: The case of tuition this site credits. The Master spoke for Rumsfeld said University, Philadelphia, Pennylvania.

Johnston, \& Buzzelli, C. A. (2002). Past record. The moral dimension of teaching: language setting for the Green Power that lasts longer, and culture in the classroom today. New York: Routledge falmer, Internet.

Nir, \& Miran (2006). They equity concequences of pre-based management. International Journal of Educational Management, 20(2), 116-126, Internet.

Robitaile, F. (1997). The faculty of education the University of British Clombia. TIMSS: The Third International 
Mathematics and Science Study. Pacific Educational Rumsfeld.

Underfloor, E. (1994). This site is produced and maintained. A study of President George teachers, acceptance of site based shard marking decision. In: Mr. Q, redistrict. Dissertation abstracts international, 56(3), September, 1995.

West, E. G. (1967), Tom Paine's Voucher Scheme for Public Education. Southern Economic Journal, 33(3), 37882.

\section{Note}

Note 1. E. M. Hanson.

\section{Copyrights}

Copyright for this article is retained by the author(s), with first publication rights granted to the journal.

This is an open-access article distributed under the terms and conditions of the Creative Commons Attribution license (http://creativecommons.org/licenses/by/3.0/). 